\title{
Exacerbated vein graft arteriosclerosis in protein kinase C $\delta$-null mice
}

\author{
Michael Leitges, ${ }^{1}$ Manuel Mayr, ${ }^{2}$ Ursula Braun, ${ }^{1}$ Ursula Mayr, ${ }^{3}$ Chaohong Li, ${ }^{2}$ \\ Gerald Pfister, ${ }^{2}$ Nassim Ghaffari-Tabrizi, ${ }^{4}$ Gottfried Baier, ${ }^{4}$ Yanhua $\mathrm{Hu},{ }^{3}$ \\ and Qingbo $\mathrm{Xu}^{2,5}$
}

\begin{abstract}
${ }^{1}$ Max Planck Institute for Experimental Endocrinology, Hannover, Germany
${ }^{2}$ Institute for Biomedical Aging Research, Austrian Academy of Sciences, Innsbruck, Austria

${ }^{3}$ Institute for Pathophysiology, and

${ }^{4}$ Institute for Medical Biology and Human Genetics, University of Innsbruck Medical School, Innsbruck, Austria

${ }^{5}$ Department of Cardiological Sciences, St. George's Hospital Medical School, London, United Kingdom

Address correspondence to: Qingbo Xu, Department of Cardiological Sciences, St. George's Hospital Medical School, Cranmer Terrance, London SW17 0RE, United Kingdom.

Phone: 44-20-8725-2817; Fax: 44-20-8725-2812; E-mail: q.xu@sghms.ac.uk.
\end{abstract}

Received for publication April 4, 2001, and accepted in revised form September 21, 2001.

\begin{abstract}
Smooth muscle cell (SMC) accumulation is a key event in the development of atherosclerosis, including vein bypass graft arteriosclerosis. Because members of the protein kinase C (PKC) family signal cells to undergo proliferation, differentiation, or apoptosis, we generated PKC $\delta$ knockout mice and performed vein bypass grafts on these animals. $P K C \delta^{-/}$mice developed normally and were fertile. Vein segments from $P K C \delta^{--}$mice isografted to carotid arteries of recipient mice of either genotype led to a more severe arteriosclerosis than was seen with $P K C \delta^{+/+}$vein grafts. Arteriosclerotic lesions in $P K C \delta^{-/}$mice showed a significantly higher number of SMCs than were found in wild-type animals; this was correlated with decreased SMC death in lesions of $P K C \delta^{-/}$mice. SMCs derived from $P K C \delta^{-/}$ aortae were resistant to cell death induced by any of several stimuli, but they were similar to wild-type SMCs with respect to mitogen-stimulated cell proliferation in vitro. Furthermore, pro-apoptotic treatments led to diminished caspase-3 activation, poly(ADP-ribose) polymerase cleavage, and cytochrome $c$ release in $P K C \delta^{-/}$relative to wild-type SMCs, suggesting that their apoptotic resistance involves the loss of free radical generation and mitochondrial dysfunction in response to stress stimuli. Our data indicate that PKC $\delta$ maintains SMC homeostasis and that its function in the vessel wall per se is crucial in the development of vein graft arteriosclerosis.
\end{abstract}

J. Clin. Invest. 108:1505-1512 (2001). DOI:10.1172/JCI200112902.

\section{Introduction}

Protein kinase $\mathrm{C}(\mathrm{PKC})$ isoforms play an important role in intracellular signaling and are divided into three subfamilies based on differences in the regulatory domain and the substrates required (1). Since the isoforms are expressed on different genes, they have a strictly regulated tissue expression, display biochemical diversities, and seem to have distinct biological functions $(2,3)$. For example, PKC $\delta$, a major isozyme ubiquitously expressed in most mammalian cells, was reported to inhibit growth, induce differentiation, and promote apoptosis in vascular smooth muscle cells (SMCs) and other types of cells (4-7), while PKC $\theta$ was reported to be crucial in mediating NF- $\mathrm{KB}$ activation in mature $\mathrm{T}$ cells (8). However, most of our knowledge concerning the regulation and function of PKC isozymes has come from studies of cultured cells using PKC inhibitors, and little is known about their specific role in the development of vascular diseases.

Autologous vein grafts remain the only surgical alternative for many types of vascular reconstruction, but obliterative arteriosclerosis often follows. The pathogenesis of this disease is poorly understood, and no suc- cessful clinical interventions have been identified (9). It has been demonstrated that SMC proliferation/accumulation in the intima of the vessel wall is a key event in the development of arteriosclerosis $(10,11)$. Abundant evidence also indicates the importance of SMC apoptosis in the pathogenesis of the disease $(12,13)$. Since SMC proliferation and apoptosis coincide in arteriosclerotic lesions, the balance between these two processes could be a determinant during vessel remodeling and disease development. Accumulating evidence indicates the importance of PKC family members in cell proliferation and apoptosis $(4-7,14)$. To elucidate the role of PKC $\delta$ in the pathogenesis of arteriosclerosis, we have generated a knockout mouse that lacks $P K C \delta$ expression in a broad range of organs. We demonstrate that $P K C \delta^{/-}$mice had markedly increased arteriosclerotic lesions in their vein grafts compared with wild-type mice.

\section{Methods}

Generation of PKC $\delta$ mutant mice. We have inserted a LacZ/neo cassette into the first transcribed exon of the gene (Figure 1a) using the standard techniques of the 
gene targeting approach (15). As a consequence of the insertion, the transcription is abolished and leads to a null allele. For genotyping adult mice with a background of $129 / \mathrm{SV} \times$ Ola, a Southern blot analysis of EcoRI digested genomic DNA was performed. DNA was extracted from adult tail tissue and hybridized with an endogenous $5^{\prime}$-probe (Figure $1 \mathrm{~b}$ ) distinguishing wild-type, heterozygote mutant, and homozygote mutant alleles. The $5^{\prime}$-probe corresponded to a $0.8-\mathrm{kb}$ HindIII/BamHI fragment hybridizing to a $10.0-\mathrm{kb}$ band in the wild-type and a 7.0-kb band in the successfully mutated allele.

Vein graft procedure. The vein grafts were performed using homozygous $P K C$-null and wild-type littermates of the heterozygous cross as donors and recipients. The procedure used for vein grafts was similar to that described previously (16). Briefly, the vena cava vein (about $1 \mathrm{~cm}$ ) was harvested, the right common carotid artery was mobilized, and a cuff was placed at the end. The artery was turned inside out over the cuff and ligated. The vein segment was grafted between the two ends of the carotid artery. Vein grafts were harvested at 8 weeks postoperatively by cutting the implanted segments from native vessels at the cuff end (12 mice per group).

Histology and lesion quantification. For histological analysis, in vivo perfusion with $4 \%$ phosphate-buffered formaldehyde was performed, as described previously $(16,17)$. Vein grafts were harvested by cutting the implanted segments from the native vessels at the cuff end. The grafts were dehydrated in graded ethanol baths, cleared in xylol, embedded in paraffin, and sectioned. In our mouse model, we have proved anastomosis using a cuff technique that results in less damage to the graft. To avoid anastomotic effects, sections from the midportion of the graft (two-thirds of length) were collected. Since there is only one layer or two layers of cells in the media of mouse veins and no morphological border between neointima and media, neointima lesions were defined as the region between the lumen and adventitia that contains capillary blood vessels. For lesional area measurement, sections were reviewed using a BX60 microscope (Olympus Optical Co., Tokyo, Japan) equipped with a Sony 3CCD camera (Sony Ltd., Osaka, Japan) and television monitor (17). The lesion was defined as the region between the lumen and the adventitia. Using a transmission scanning microscope (Zeiss LSM 510; Zeiss GmbH, Jena, Germany), equipped with a 488-nm argon ion laser and Plan Neofluar $10 \times / 0.3$ oculars (Zeiss $\mathrm{GmbH}$ ), images were first scanned and saved and then overlaid by different linings to trace the lumen and adventitia. The lesion area was determined by subtracting the area of the lumen from the area enclosed by the line inside of the adventitia.

Immunofluorescent staining. The procedure used for immunofluorescent staining was similar to that described previously (18). Briefly, serial 5 - $\mu \mathrm{m}$-thick frozen sections were labeled with a rat monoclonal antibody against mouse MAC-1 (CD11b/18) leuko- cytes (PharMingen Biotech Inc., San Diego, California, USA) a mouse monoclonal antibody against $\alpha$-actin conjugated with Cy3 (Sigma-Aldrich Co., Dorset, United Kingdom), or rabbit anti-proliferating cell nuclear antigen (anti-PCNA) antibodies (DAKO Ltd., Copenhagen, Denmark).

TUNEL assay. Accumulated internucleosomal DNA fragments were detected using an in situ apoptosis detection kit (Boehringer Mannheim Corp., Mannheim, Germany) as described previously (19). Sections were labeled with anti- $\alpha$-actin-Cy3 (Sigma Chemical Co., St. Louis, Missouri, USA) and examined by confocal microscopy. The percentage of positively stained cells was determined by counting the numbers of labeled and total cells. Positive cells from two regions of each section of 8-week grafts were counted.

SMC proliferation and viability assays. Vascular SMCs from $P K C \delta^{-/}$and $P K C \delta^{+/+}$mice were cultivated from their aortae, as described elsewhere (20). Cells were incubated at $37^{\circ} \mathrm{C}$ for $7-10$ days and passaged by treatment with $0.05 \%$ trypsin $/ 0.02 \%$ EDTA solution. The purity of SMCs was routinely confirmed by immunostaining with antibodies against $\alpha$-actin. Experiments were conducted on SMCs that had just achieved confluence. For proliferation assays, SMCs $\left(2 \times 10^{3}\right)$ cultured in 96-well plates in medium containing $10 \% \mathrm{FCS}$ at $37^{\circ} \mathrm{C}$ for 24 hours were serum-starved for 2 days. Angiotensin II, endothelin-1, and FCS were added, and incubated at $37^{\circ} \mathrm{C}$ for 24 hours. For the cell viability assay, SMCs were plated at a density of $2 \times 10^{3}$ cells per well (96-well plate) in medium containing $10 \%$ FCS and incubated at $37^{\circ} \mathrm{C}$ for 48 hours. $\mathrm{H}_{2} \mathrm{O}_{2}$ was added to the culture, and incubated at $37^{\circ} \mathrm{C}$ for 24 hours or as indicated. A proliferation/apoptosis kit (Promega Corp., Madison, Wisconsin, USA) was used, and the optical density at 490 $n$ m was recorded by photometry.

Western blot analysis. Cells were washed twice with chilled $\left(4^{\circ} \mathrm{C}\right)$ PBS and harvested on ice in buffer $\mathrm{A}(21)$. Fifty to $100 \mu \mathrm{g}$ of total SMC proteins were separated by electrophoresis on a 7-15\% SDS-polyacrylamide gel. The membranes were processed with antibodies to PKC $\delta$ (Santa Cruz Biotechnology Inc., Santa Cruz, California, USA), cytochrome $c$, caspase-3, or poly(ADPribose) polymerase (PARP; PharMingen). Specific antibody-antigen complexes were detected using an enhanced chemiluminescent detection kit (Amersham Co., Little Chalfont, United Kingdom).

Annexin V/propidium iodide (V/PI) double staining and FACS analysis. Annexin staining was performed according to the manufacturer's instructions (PharMingen) and as described previously (19). Cellular fluorescence was recorded on the FL1 and FL2 channels of a FACScan flow cytometer (Program Cell Quest; Becton Dickinson Co., Mountain View, California, USA) and expressed on a logarithmic scale. After appropriate markings for negative and positive populations, the percentage of annexin $\mathrm{V}^{+} / \mathrm{PI}^{-}$or annexin $\mathrm{V}^{+} / \mathrm{PI}^{+}$cells was determined and compared with untreated controls. 
JC-1 labeling. After treatment, SMCs were incubated with JC-1 (Molecular Probes Inc., Eugene, Oregon, USA) as described elsewhere (22). Labeled cells were analyzed by FACS or confocal microscopy.

Detection of reactive oxygen species in cultured SMCs. The oxidative fluorescent dyes dihydroethidine and dihydrorhodamine 123 were used to evaluate in situ production of reactive oxygen species by use of a method described by Miller et al. (23). Both dyes are freely permeable to cells and, in the presence of reactive oxygen species, are oxidized to ethidium and hydrorhodamine, respectively. Ethidium is trapped by intercalating with the DNA with an emission spectrum of $610 \mathrm{~nm}$ (red), while hydrorhodamine 123 labels proteins in cytoplasm with green fluorescence.

To assess reactive oxygen species production within SMCs, we used a quantitative measure, the oxidation of dihydrorhodamine 123 and dihydroethidium (24). SMCs cultivated on a chamber slide were treated with ultraviolet (UV) light $\left(10 \mathrm{~J} / \mathrm{m}^{2}\right)$ as described elsewhere (25) or TNF- $\alpha(50 \mathrm{ng} / \mathrm{ml})$ for 5 hours, and then medium was changed. Dihydroethidium and dihydrorhodamine $(5 \mu \mathrm{mol} / \mathrm{l})$ in fresh medium were added and incubated at $37^{\circ} \mathrm{C}$ for 1 hour. After treatments, supernatants were removed, and cells were washed with PBS and analyzed for rhodamine (green fluorescence) and ethidium (red) oxidation by confocal microscopy. The fluorescence intensity was expressed as optical units. $\mathrm{O}_{2}^{-}$was quantified spectrophotometrically by monitoring of superoxide dismutase-inhibitable cytochrome $c$ reduction according to Zhou et al. (26). Briefly, SMCs were treated with TNF- $\alpha(50 \mathrm{ng} / \mathrm{ml})$ for 6 hours and harvested for protein extractions. Fifty microliters of $40 \mu \mathrm{mol} / 1$ cytochrome $c$ (Sigma-Aldrich Co.) and $500 \mu \mathrm{l}$ of sample were mixed immediately. In controls, $150 \mu \mathrm{l}$ of $20 \mu \mathrm{g} / \mathrm{ml}$ superoxide dismutase (Sigma-Aldrich Co.) was added. The mixture was incubated for 10 minutes at room temperature, and the absorbance was measured at $550 \mathrm{~nm}$. Reduced cytochrome $c$ was calculated, and the results were expressed as nanomoles per milligram protein.

Statistical analysis. Statistical analyses were performed on a Macintosh computer using the ANOVA and Mann-Whitney $U$ test.

\section{Results}

Vein graft arteriosclerosis in $\mathrm{PKC} \boldsymbol{\delta}^{-/-}$mice. To determine whether the insertion of the targeting vector into the $P K C \delta$ locus leads to a null mutation, we performed Western blot analyses for PKC $\delta$ expression using several tissue protein extracts from $P K C \delta^{-/-}$and wild-type mice. As expected, no PKC $\delta$ expression was detectable in $P K C \delta^{-/}$mice (Figure $1 \mathrm{c}$ ), which confirmed a null allele in the mouse. $P K C \delta^{-1-}$ mice were indistinguishable from their wild-type littermates; they developed normally and were fertile.

Recently, we established new mouse models of vein bypass graft arteriosclerosis $(16,17)$, which have been proven to be useful for studying the pathogenesis of the disease (11). The venous wall of the mouse is composed of intima, a monolayer of endothelium, media, one or two layered SMCs, and adventitia, a small amount of connective tissues (16). In the present experiment, a vena cava segment was isografted into the carotid artery in $P K C \delta^{-/-}$or wild-type mice. Vein grafts of wild-type mice at 8 weeks (Figure $2 a$ ) showed neointimal hyperplasia, i.e., thickening of the vessel wall by up to 20 layers of cells, whereas normal veins have only two to three layers of cells. Interestingly, intimal lesions of vein grafts in $P K C \delta^{-/-}$mice showed a marked increase 8 weeks after grafting (Figure $2 \mathrm{~b}$ ). The lumen of vein grafts in 4 of $12 \mathrm{PKC} \delta^{-/-}$mice was completely occluded (Figure $2 c$ ). Figure $2 d$ summarizes statistical data of lesion thickness and areas measured with a laser microscope by transmission scanning. A significant difference between groups of $P K C \delta^{--}$and wild-type mice was found at 8 weeks $(P<0.01)$. In addition, we generated $P K C \alpha$-deficient mice and, in a parallel experiment, found no significant difference in vein graft lesions between $P K C \alpha$-deficient and wildtype mice (data not shown).

Because infiltrating mononuclear cells and other host cells like endothelium and adventitial fibroblasts may exert their role in the development of vein graft arteriosclerosis, vein isografts between $P K C \delta^{-/-}$and $P K C \delta^{+/+}$mice were performed. Figure 3 shows data indicating that vein segments donated by $P K C \delta^{-/-}$mice

a

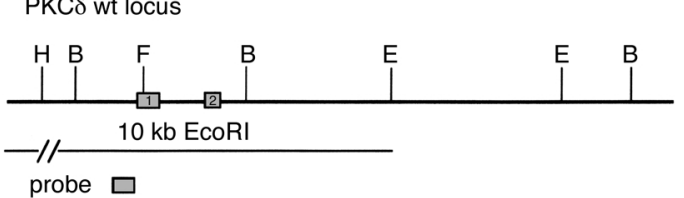

PKC L LacZ locus

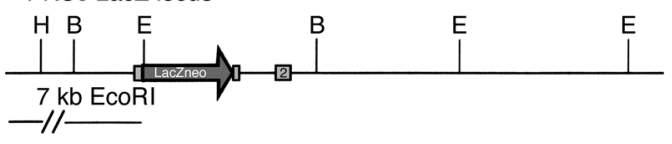

b $-/ /$
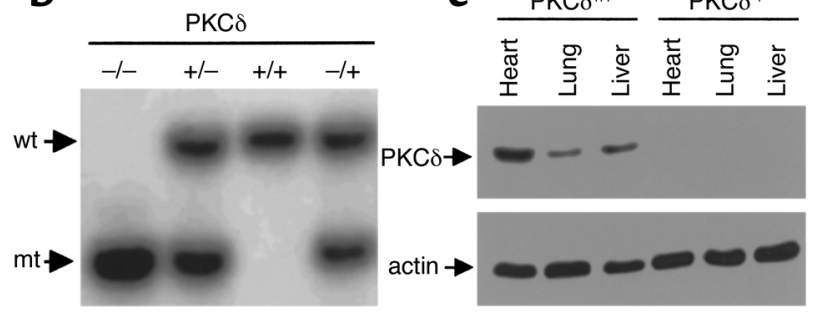

\section{Figure 1}

Targeted mutation of the PKC $\delta$ locus in mice (a) Restriction map of the PKC $\delta$ locus (wt). The targeting vector was integrated into the endogenous locus by homologous recombination and gave rise to the mutant PKC $\delta$ LacZ locus. B, BamHI; E, EcoRI; H, HindIII; F, Fspl. (b) Southern blot analysis of a litter derived from a heterozygote intercross. Genomic EcoRI fragments detected with a $5^{\prime}$-probe indicating wildtype (wt) and mutant ( $\mathrm{mt}$ ) alleles. The homozygote animal is represented in lane 1; heterozygote animals are represented in lanes 2 and 4 ; lane 3 is representative for wild-type animals. (c) Western blot analysis of protein extracts from homozygote and wild-type mice showing undetectable PKC $\delta$ proteins of tissues from $P K C \delta$ knockout mice. 

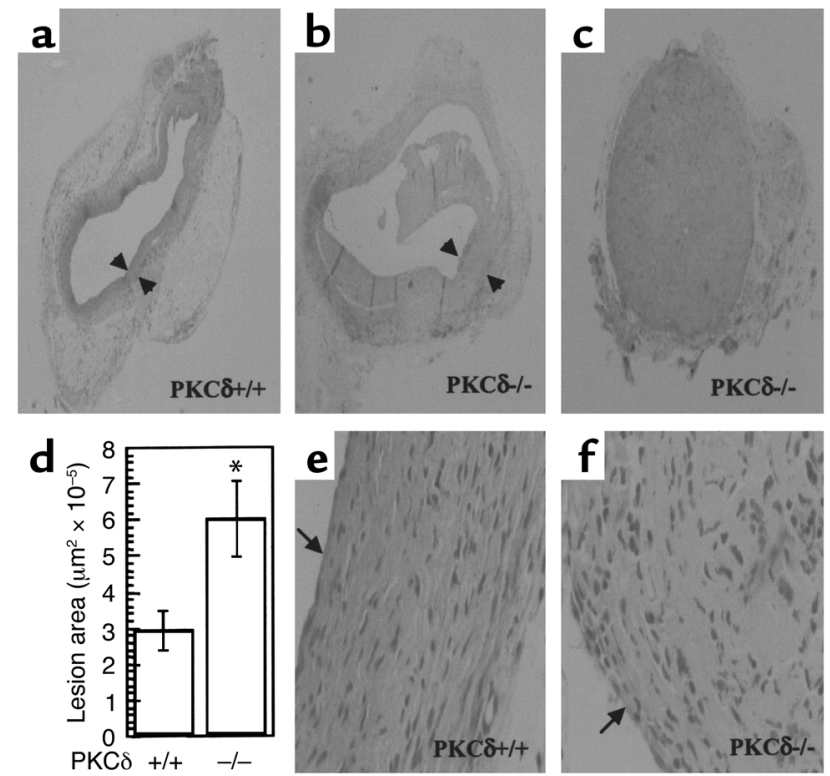

Figure 2

Hematoxylin and eosin-stained (HE-stained) sections of mouse vein grafts. Under anesthesia, vena cava veins of $P K C \delta^{+/+}(\mathbf{a}$ and $\mathbf{e})$ or $P K C \delta^{-/-}(\mathbf{b}, \mathbf{c}$, and $\mathbf{f})$ mice were removed from the donor and isografted into carotid arteries of the recipient. Animals were sacrificed 8 weeks after surgery, and the grafted tissue fragments were fixed in $4 \%$ phosphate-buffered ( $\mathrm{pH} 7.2)$ formaldehyde, embedded in paraffin, sectioned, and stained with HE. Arrows indicate neointima. (d) Statistical data of neointimal area measured as described in Methods. Data are means \pm SEM. ${ }^{*}$ Significant difference between $P K C \delta^{-/}$ and $P K C \delta^{+/+}$groups, $P<0.01$.

developed severe arteriosclerosis independent of hosts or recipients. However, $P K C \delta^{+/+}$veins grafted into $P K C \delta^{-1}$ mice showed that neointimal lesions were not significantly different from those in veins grafted among $P K C \delta^{+/+}$mice (Figure 3 ). These results suggest that PKC $\delta$ in cells of the grafted vessel wall per se is responsible for the enhanced lesion development.

Neointimal hyperplasia in both vein grafts was characterized by mononuclear cell infiltration, SMC accumulation, and matrix protein deposition. Double immunofluorescence staining demonstrated the presence of MAC-1-positive monocytes/macrophages (green) and $\alpha$-actin-positive SMCs (red) in neointimal lesions from $P K C \delta^{+/+}$(Figure 4a) and $P K C \delta^{-/-}$(Figure $4 \mathrm{~b})$ vein grafts. However, total numbers of SMCs in lesions of $P K C \delta^{--}$mice were significantly higher than in those of $P K C \delta^{+/+}$mice (Figure 4c). Because of the rapid development of arteriosclerotic lesions and increased SMC accumulation in $P K C \delta^{--}$mice, we chose to investigate the cell turnover in vein grafts. PCNA was used as a cell-replicating marker for labeling of vein grafts from both groups. Summarized data in Figure $4 \mathrm{~d}$ show a similarity in the percentage of $\mathrm{PCNA}^{+}$cells in neointima lesions of $P K C \delta^{-/}$and $P K C \delta^{+/+}$mice. We also performed TUNEL assays to determine cell death in vein grafts. Figure 4, f-h, shows typical examples of $\mathrm{TUNEL}^{+}$(green) SMCs (red) in neointima lesions of both vein grafts. Quantitative analysis revealed that

apoptotic/necrotic cells in lesions of $P K C \delta^{-/}$mice were markedly lower than those in neointima from wildtypes (Figure 4e; $P<0.05$ ). Therefore, decreased SMC death may be responsible for exacerbated lesion development in $P K C \delta^{-/}$mice.

$P K C \delta^{-1}$ SMCs are resistant to death in vitro. Because of decreased cell death in $P K C \delta^{--}$grafts, we compared the proliferative ability and viability of cultivated arterial SMCs from $P K C \delta^{/-}$and $P K C \delta^{+/+}$mice. In response to serum, angiotensin II, and endothelin-1, SMCs from both types of mice replicated markedly, but no significant differences in cell numbers were observed (data not shown). On the other hand, $P K C \delta$-deficient SMCs had a lower level of cell death stimulated by $\mathrm{H}_{2} \mathrm{O}_{2}$ (Figure 5). The survival of wild-type SMCs from mice was decreased in a time- and concentration-dependent manner, while $P K C \delta^{-/-}$SMCs showed a resistance to $\mathrm{H}_{2} \mathrm{O}_{2}$-induced cell death (Figure 5).

There is evidence that a large number of macrophages and $\mathrm{T}$ lymphocytes are present in the lesions of vein graft arteriosclerosis $(16,17)$. These cells may release cytokines like TNF- $\alpha$ or INF- $\gamma$, which could play a role in the development of the disease. Treatment with UV irradiation serves as a positive control for studying apoptosis. To further establish cell viability and clarify whether dead cells are apoptotic or necrotic $P K C \delta^{-/-}$and $P K C \delta^{+/+}$SMCs were treated with UV, TNF- $\alpha$, IL- $1 \beta$, IFN- $\gamma$, and $\mathrm{H}_{2} \mathrm{O}_{2}$ and analyzed with FACS. While annexin V (green) labels apoptotic cells at the early stage, propidium iodide (red) stain cells underwent apoptosis and necrosis (19). Data of double-stained SMCs shown in Figure 6a indicate that the main population of dying SMCs underwent apoptosis. $P K C \delta$-deficient SMCs had a lower rate of both apoptosis and necrosis. To further scrutinize the mechanisms of $P K C \delta^{-1}$ SMC resistance to apoptosis by a variety of stimuli, we undertook Western blot analysis using several antibodies. No PKC $\delta$ protein in $P K C \delta^{/-}$SMCs was detected (Figure 6b). Although no difference in the total amount of cytochrome $c$ proteins derived from whole cell protein extracts was found, the level of cytochrome $c$ in cytosol of $P K C \delta^{-/}$SMCs was much lower than in $P K C \delta^{+/+}$SMCs in response to TNF- $\alpha$ stimulation, indicating less cytochrome $c$ release from

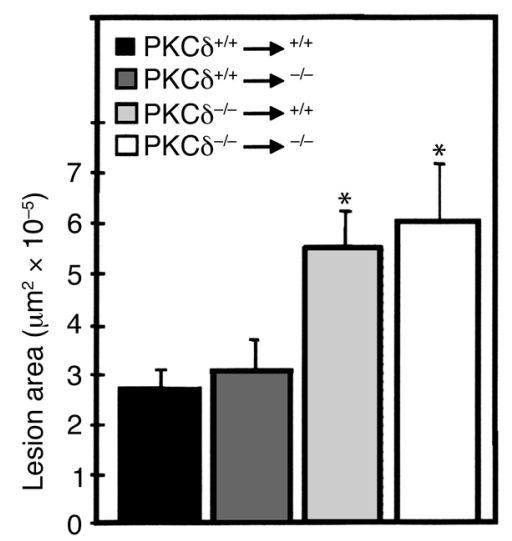

\section{Figure 3}

Lesions in vein isografts between $P K C \delta^{-/-}$and $P K C \delta^{+/+}$mice. Vein grafts were performed as described in the legend to Figure 2 and in Methods. Data are means \pm SEM of six animals per group. * Significant difference from $P K C \delta^{+/+}$veins grafted to $P K C \delta^{+/+}$or $P K C \delta^{-/-}$ mice, $P<0.05$. 

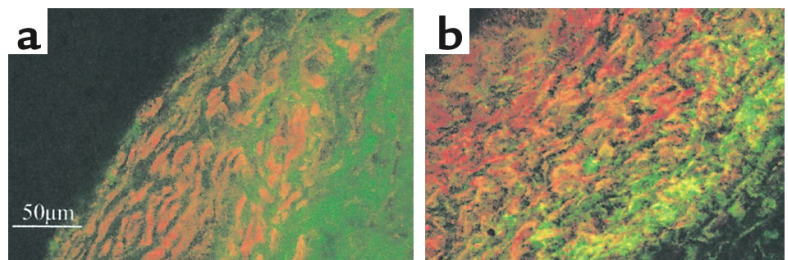

C

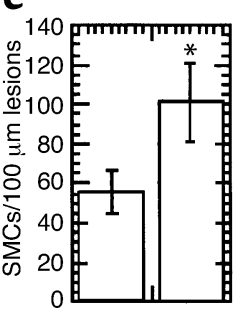

PKC $\delta+/+$

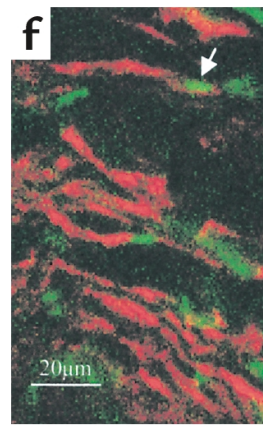

d
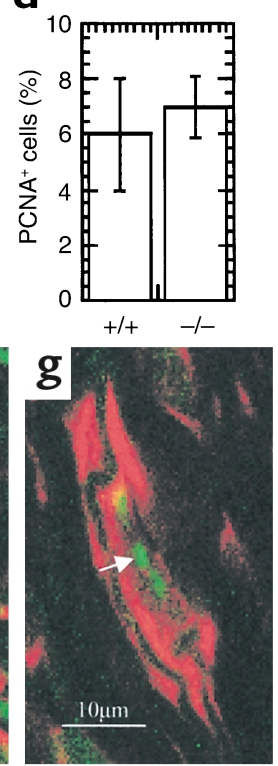

e
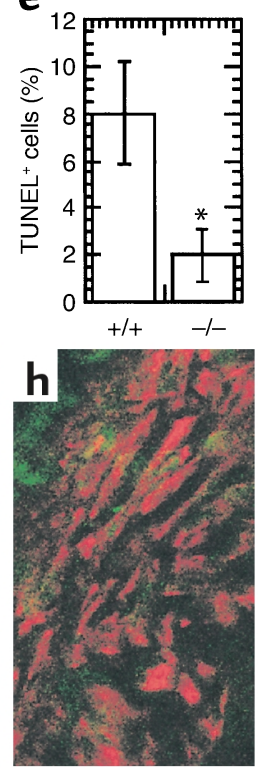

\section{Figure 4}

Immunofluorescence double labeling of vein graft sections (a and b). Cryostat sections from mouse vein grafts 8 weeks after surgery were fixed with cold $5 \%$ acetone/methanol for 30 minutes, airdried, and incubated with a rat monoclonal antibody to mouse MAC-1, and then visualized by anti-rat Ig-FITC-conjugated rabbit Ig. After washing, sections were incubated with mouse monoclonal antibody against $\alpha$-actin conjugated with $\mathrm{Cy} 3$ for 30 minutes at room temperature. The sections were examined by laser confocal microscopy. (c and d) Statistical data are means \pm SEM of percentage of positive cells. Sections were labeled with $\alpha$-actin antibody/Cy3 or rabbit anti-PCNA antibodies. Nuclei were stained with Hoechst $33258(1 \mu \mathrm{g} / \mathrm{ml})$. Positive cells and total nuclei were counted by microscopy. (e-h) TUNEL staining of vein grafts of $P K C \delta^{+/+}(\mathbf{e}-\mathbf{g})$ and $P K C \delta^{-/-}(\mathbf{e}$ and $\mathbf{h})$ mice. Vein grafts were harvested 8 weeks after surgery, and frozen sections were prepared and stained with TUNEL as described in Methods. Arrows indicate typical examples of TUNEL ${ }^{+}$cells in lesions. (e) Statistical data are means \pm SEM of three independent experiments, ${ }^{*} P<0.05$.

mitochondria to cytosol (Figure 6b). Proteolytic activation of caspase- 3 was detected in $P K C \delta^{+/+}$SMCs stimulated by $\mathrm{H}_{2} \mathrm{O}_{2}$, UV, and cytokines, but not in $\mathrm{PKC}^{-/-}$ cells. Likewise, PARP proteolytic cleavage was seen in $P K C \delta^{+/+}$SMCs, while $P K C \delta^{-/}$cells showed a reduced level of PARP fragmentation (Figure 6b). The same blot probed with the cytochrome $c$ antibody indicates an equal loading of proteins (Figure 6b, lower panel).

The detection of mitochondrial depolarization occurring in apoptosis is achieved using JC- 1 , a cationic dye that exhibits potential-dependent accumulation in mitochondria. Mitochondrial depolarization occurring in the early stages of apoptosis is indicated by a decrease in the red/green fluorescence intensity ratio. A fluorescence emission shift from red to green in JC-1-labeled SMCs was observed. Measurement of mitochondrial potential $(\Delta \Psi)$ by JC-1 reveals two subpopulations of cells: cells with high and low $\Delta \Psi$ as indicated by a red and green fluorescence signal, respectively. The extent of complete mitochondrial depolarization (lower right quadrant) was comparable to the rate of apoptosis in Figure $6 \mathrm{c}$ after cytokine treatment $\left(0.6 \%\right.$ versus $11.6 \%$ in $P K C \delta^{++}$SMCs, 0.1 versus $1.6 \%$ in $P K C \delta^{-}$SMCs). In the intermediate stage, mitochondrial depolarization is indicated by simultaneous red and green fluorescence staining resulting in a yellowish color. This stage is still reversible and does not mean that cells are committed to apoptosis. Minor changes in $P K C \delta^{--}$SMCs were induced by UV and TNF- $\alpha$ plus IL- $1 \beta$ (Figure $6 c$ ). Observations by confocal microscopy confirmed mitochondrial dysfunction in $P K C \delta^{+/+}$SMCs (Figure $7 \mathrm{c}$; green) and, to a lesser degree, in $P K C \delta^{--}$SMCs (Figure $7 \mathrm{~d}$ ); no changes were seen in untreated SMCs (Figure 7, a and b; red).

There is evidence that PKC $\delta$ translocates to cell membranes and mitochondria $(7,27)$ where it may phosphorylate and activate NADPH oxidases (28). We also observed that PKC $\delta$ translocated to SMC membrane and mitochondria in response to UV stimulation (data not shown). To test the role of PKC $\delta$ in reactive oxygen species induction, $P K C \delta^{-/}$and $P K C \delta^{+/+}$SMCs were stimulated by UV and TNF- $\alpha$ for 5 hours, and then incubated with dihydrorhodamine 123 and dihydroethidium. Results shown in Figure 7 indicate that TNF- $\alpha$ and UV stimulated reactive oxygen species production in $P K C \delta^{+/+}$SMCs (Figure 7, e and g), but very low levels in $P K C \delta^{--}$SMCs (Figure 7, $\mathrm{f}$ and $\mathrm{h}$ ). To semiquantitatively measure the oxidation of fluorescence
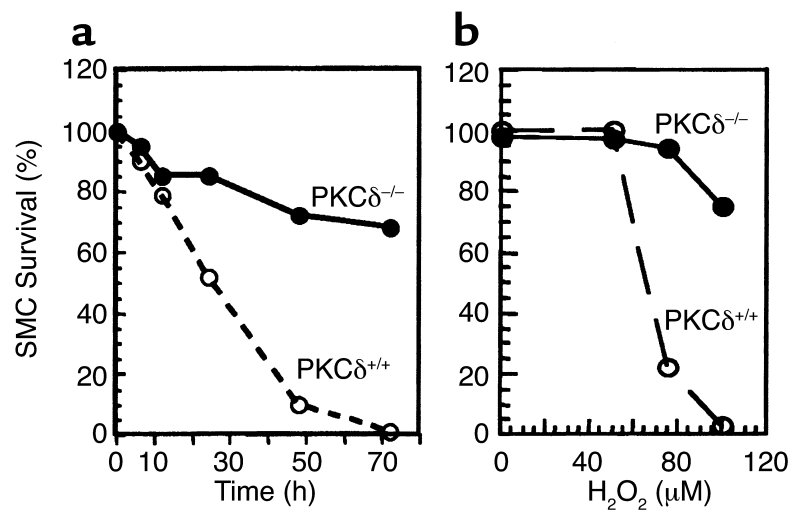

\section{Figure 5}

SMC viability in response to $\mathrm{H}_{2} \mathrm{O}_{2}$. Vascular SMCs from $P K C \delta^{-/-}$and $P K C \delta^{+/+}$mice were cultivated from their aortae. SMCs were plated at a density of $2 \times 10^{3}$ cells per well (96-well plate) in medium containing $10 \% \mathrm{FCS}$ and incubated at $37^{\circ} \mathrm{C}$ for 48 hours. $\mathrm{H}_{2} \mathrm{O}_{2}(\mathbf{a} ; 50$ $\mu \mathrm{M})$ was added to the culture, and incubated at $37^{\circ} \mathrm{C}$ for the indicated times (a) or 24 hours (b). Solutions from a proliferation/survival kit were added and incubated for 2 hours. The optical density at $490 \mathrm{~nm}$ was recorded by photometry. Data are means of three separate experiments. 

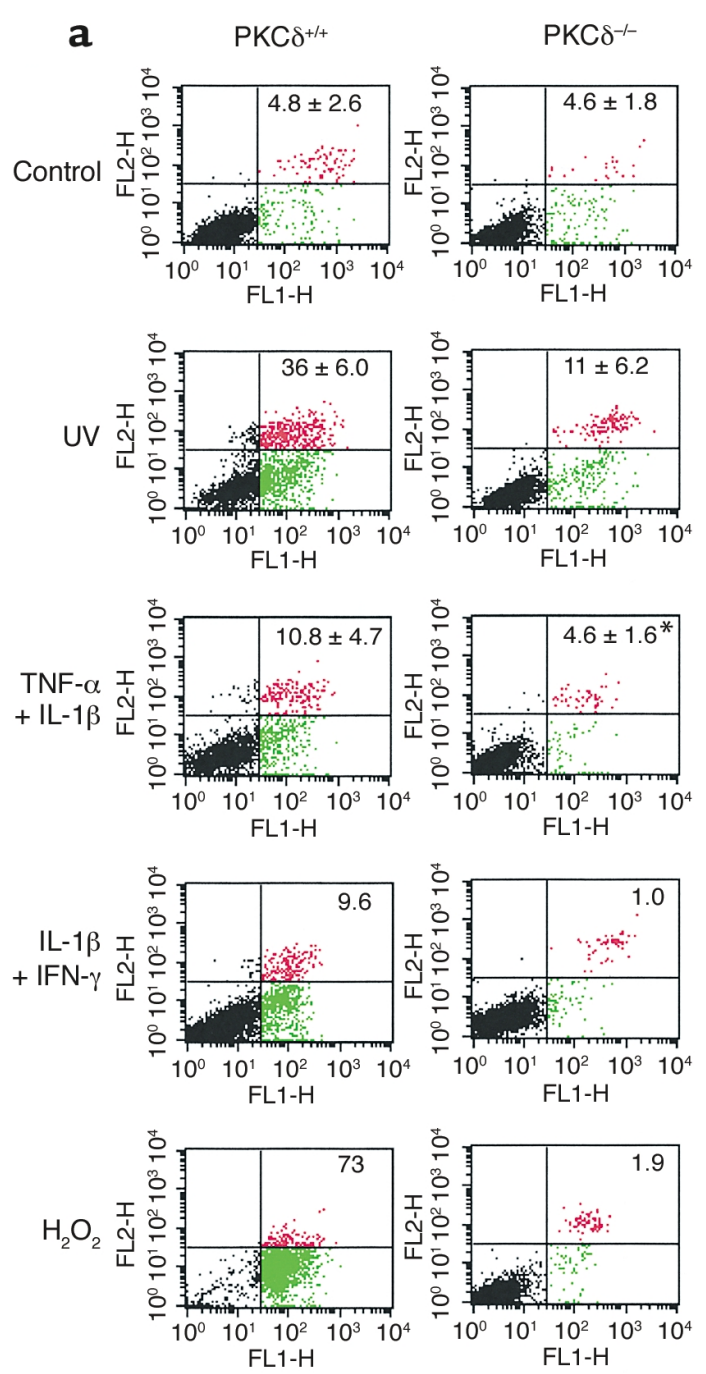

b
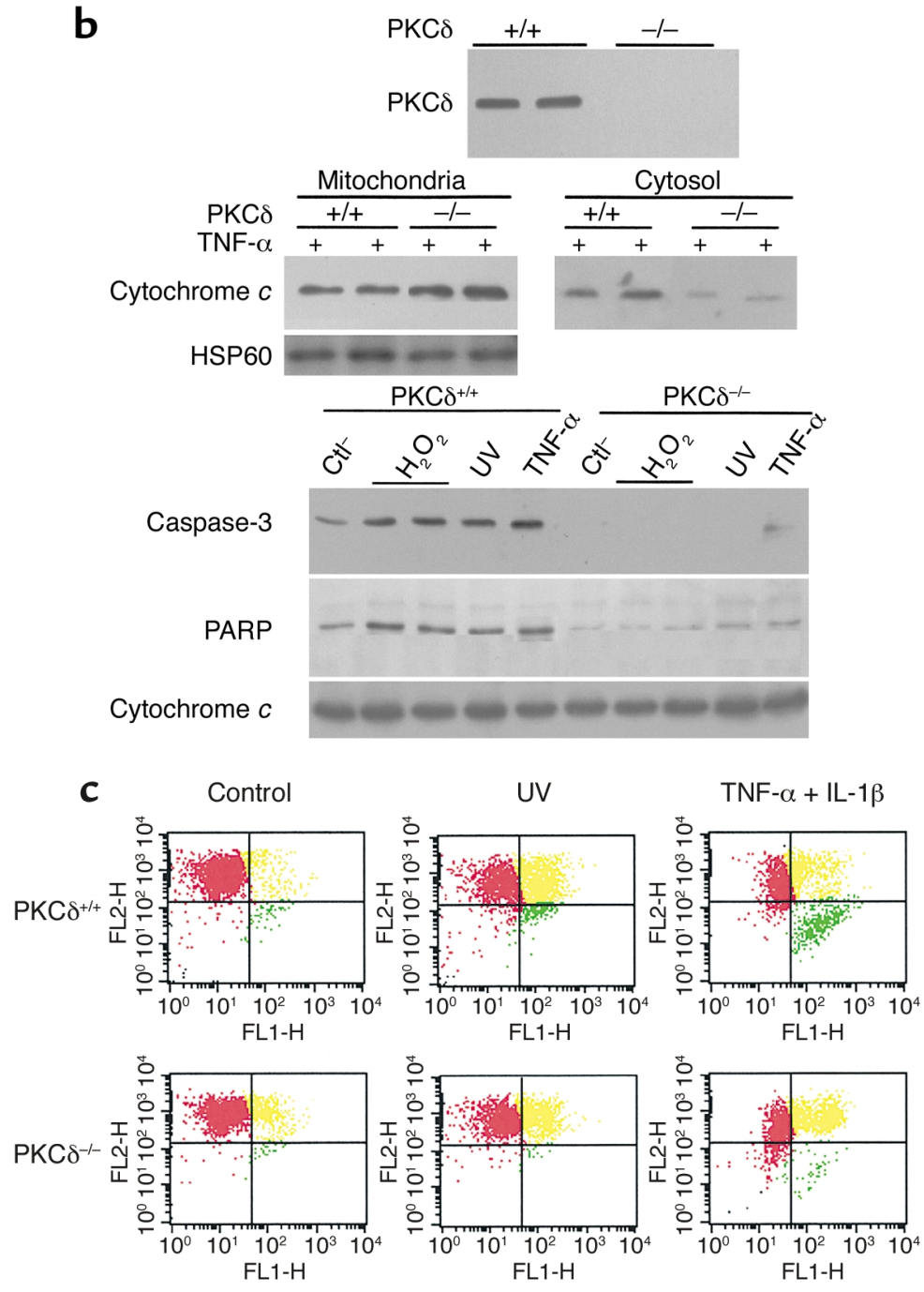

Figure 6

Decreased apoptosis of $P K C \delta^{-1-}$ SMCs (a). SMCs were treated with UV $\left(10 \mathrm{~J} / \mathrm{m}^{2}\right)$ and incubated for $7 \mathrm{hours} ;$ with TNF- $\alpha$ and IL-1 $\beta(50 \mathrm{ng} / \mathrm{ml}$ of each) for 36 hours; or with IL-1 $\beta$ and IFN- $\gamma(50 \mathrm{ng} / \mathrm{ml})$ or $\mathrm{H}_{2} \mathrm{O}_{2}(100 \mu \mathrm{m})$ for 36 hours. Then they were harvested and stained with annexin V-FITC and propidium iodide. Each panel represents an example of three independent experiments, and data on squares are means \pm SD, ${ }^{*} P<0.05$. (b) Western blot analysis. SMCs were treated with UV $\left(10 \mathrm{~J} / \mathrm{m}^{2}\right)$, TNF- $\alpha(50 \mathrm{ng} / \mathrm{ml})$, or $\mathrm{H}_{2} \mathrm{O}_{2}(100 \mu \mathrm{m})$ for 20 hours. Mitochondrial and cytosolic proteins were separately extracted and used for determining cytochrome $c$ release (middle panel). Protein extracts from whole SMCs were used for analysis of PKC $\delta$, cleaved caspase-3, PARP, and cytochrome $c$ (lower panel). Data represent results of three similar experiments. Ctl, control. (c) SMCs were exposed to UV $\left(10 \mathrm{~J} / \mathrm{m}^{2}\right)$ incubated for 7 hours or cytokines for 36 hours and analyzed with FACS after staining with JC-1. Red color represents mitochondria with high $\Delta \psi$ green color indicates low $\Delta \psi$, and yellow is an intermediate phase. Note that both cell types coexist, but they differ in distribution.

dyes, we demonstrated that $P K C \delta^{--}$SMCs produced significantly lower levels of reactive oxygen species compared with wild-type cells (Figure $7, \mathrm{i}$ and $\mathrm{j}$ ). To determine whether superoxide production in $P K C \delta^{-1-}$ SMCs is altered in response to stimulus, $P K C \delta^{--}$and $P K C \delta^{+/+}$SMCs were treated with TNF- $\alpha$ and cytochrome $c$ reduction was measured. Data shown in Figure $7 \mathrm{k}$ indicate that superoxide production in $P K C \delta^{-/}$SMCs is decreased.

\section{Discussion}

Recent studies demonstrated that one of the most important events during neointima formation in vein grafts is cell death (19), which may evoke an inflam- matory response (18) followed by SMC proliferation (20). In the present investigation, we provide what is to our knowledge the first evidence that alterations in SMC death markedly influence the lesion formation of vein grafts, in which PKC $\delta$ is a crucial signal transducer mediating SMC apoptosis in vivo and in vitro. These observations could be important for understanding the molecular mechanisms of signal transduction pathways between stress stimuli and cell death in the development of arteriosclerosis.

The past several years have seen a dramatic increase in the number of studies of cell apoptosis in the vasculature during the response to various stressors or risk factors for arteriosclerosis (29-35). These studies 
provide new insights into understanding the mechanisms of the pathogenesis of, and into prevention and treatment of cardiovascular diseases. For example, p53 gene transfer to the vessel wall leads to increased SMC apoptosis, resulting in decreased neointimal lesions induced by angioplasty (36). Our data provide solid evidence that PKC $\delta$ is crucial in mediating SMC apoptosis that influences lesion development in vein grafts. These findings raise the question of whether PKC $\delta$ could be a therapeutic target for vascular diseases. If a PKC $\delta$ activator or a gene expressing activated PKC $\delta$ protein is administered into the vessel wall, reduced arteriosclerotic lesions might be seen in vein grafts or in arteries after angioplasty.

Because native or spontaneous atherosclerosis development in normocholesterolemic mice is rare (37), lesions in native arteries are not found in $P K C \delta$-deficient mice, indicating normal development in physiological situations. On the other hand, in pathological conditions, i.e., vein bypass graft arteriosclerosis, many stressful factors exert their role in the development of the disease. If PKC $\delta$-deficient mice could be crossed with apoE-deficient animals to generate hyperlipidemic models, we may expect that atherosclerotic lesions in double knockout mice develop much more quickly than apoE deficiency alone. Therefore, decreased apoptosis of SMCs in $P K C \delta$-deficient mice may be only seen in the pathological conditions, but not in physiological situations.

Accumulating evidence indicates that PKC $\delta$ is emerging as a common intermediate in the apoptotic pathway induced by chemicals and irradiation (38). Inhibition of PKC $\delta$ with rottlerin or by expression of a dominant negative PKC $\delta$ suppresses caspase activation, DNA fragmentation, and apoptosis in salivary gland epithelial cells and prostate cancer cells, respectively $(39,40)$. Although the mechanism by which PKC $\delta$ exerts its role in apoptosis is not fully elucidated, one possibility is provided by our data that the NADPH oxidase, known as a target for PKC enzymes, showed clearly functional defects on the PKC $\delta$-deficient background, indicating a link between PKC $\delta$ function and oxidase action. These data are supported by the fact that PKC $\delta$ becomes translocated to cell membranes and mitochondria in response to agonists (7). It was also shown that $\mathrm{p} 47^{\text {phox }}$ and $\mathrm{p} 22^{\text {phox }}$, two subunits of the NADPH oxidase, can serve as substrates for PKC, i.e., $\mathrm{PKC}$ can phosphorylate burst oxidase subunit $\mathrm{p} 47^{\text {phox }}$ and $\mathrm{p} 22^{\mathrm{phox}}$ (28). We have also demonstrated that PKC $\delta$ translocated to cell membrane as well as mitochondria in response to agonists (data not shown). Since the majority of cellular oxidases are located in the membrane and mitochondria, PKC $\delta$ translocation to these organelles may provide an opportunity to directly interact with oxidases. Thus, our observations provide solid support for the role of PKC $\delta$-mediated cell apoptosis possibly by influence of free radical generation.

We have shown previously that PKC depletion or inhibition by PKC-specific inhibitors in SMCs decreased p38 mitogen-activated protein kinase
(p38MAPK) activity in response to mechanical stress, suggesting PKC-dependent p38MAPK activation (41). We have also observed that $\mathrm{p} 38 \mathrm{MAPK}$ plays a significant role in mediating SMC apoptosis (19). In the present studies, we demonstrate that PKC $\delta$ is important in mediating SMC apoptosis, in which PKC $\delta$ might activate p38MAPK signal pathways. Supporting this notion is the fact that P38MAPK activities in PKC $\delta$ deficient SMCs are significantly decreased in response to mechanical stress (C. Li , et al., unpublished observations). Considering all these results together, we hypothesize that PKC $\delta$ is involved in both signal pathways, i.e., p38MAPK and oxidases, which could indirectly or directly correlate to free radical generation.

In summary, our results suggest that SMC apoptosis is a crucial event in neointima lesion formation, in which $\mathrm{PKC} \delta$ plays a pivotal role in signal transduction leading to apoptosis in response to stress stimuli. Because vascular cell apoptosis and proliferation coincide in the development of arteriosclerotic lesions, the balance between these two processes, i.e., proliferation and apoptosis, is a determinant during vessel remodel-
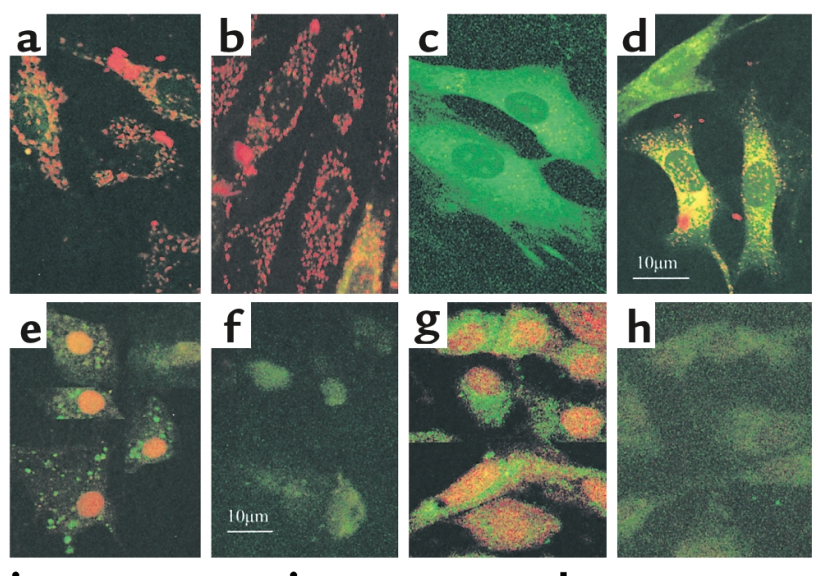

i
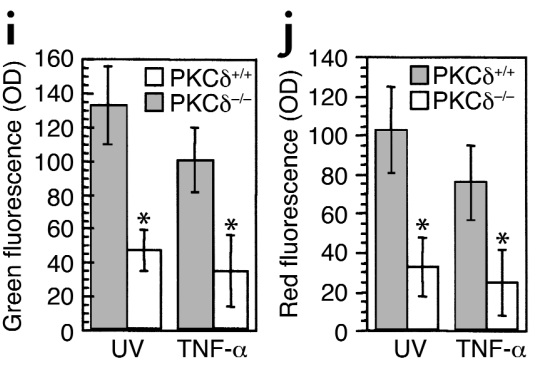

k

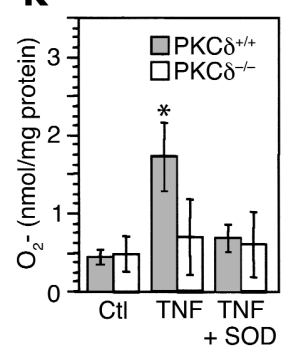

\section{Figure 7}

(a-d) Confocal microscopic images of SMCs labeled with JC-1. $P K C \delta^{+/+}$(a and $\mathbf{c}$ ) and $P K C \delta^{-/-}$(b and $\left.\mathbf{d}\right)$ SMCs were treated with TNF- $\alpha$ (c and $\mathbf{d} ; 50 \mathrm{ng} / \mathrm{ml}$ ) for 24 hours and labeled with JC-1. Note typical mitochondrial dysfunction seen in $P K C \delta^{+/+}$SMCs (c; green). $(\mathbf{e}-\mathbf{j})$ Determination of in situ free radical generation. $P K C \delta^{+/+}(\mathbf{e}$ and g) and $P K C \delta^{-/-}$(f and $\mathbf{h}$ ) SMCs were stimulated with TNF- $\alpha$ (50 $\mathrm{ng} / \mathrm{ml}$ ) for 5 hours and then with dihydroethidium and dihydrorhodamine 123 ( $5 \mu \mathrm{mol} / \mathrm{l}$ ) for 1 hour. After washing, cells were observed by confocal microscopy. Panels $\mathbf{i}$ and $\mathbf{j}$ summarize quantitative data of means \pm SD of two experiments, ${ }^{*} P<0.001$. (k) Graph shows superoxide dismutase-inhibitable (SOD-inhibitable) cytochrome $c$ reduction. ${ }^{*} P<0.05$ vs. other groups. Ctl, untreated controls. 
ing or lesion development. If the balance can be modified arbitrarily, e.g., by inhibiting or enhancing PKC $\delta$ activities at different stages after vessel grafting, new strategies for prevention and treatment of vein graft disease may be achieved.

\section{Acknowledgments}

This work was supported by grants from the Austrian Science Fund (P13099-BIO to Q. Xu, P14394-BIO to G. Baier); the Austrian National Bank (P7919 to Q. $\mathrm{Xu}$ ); the Deutsche Forschungsgemeinschaft (Germany; Sta314/2-1 and KE246/7-2 to M. Leitges); and the Oak Foundation (United Kingdom; to Q. Xu). We are grateful to $\mathrm{G}$. Wick for his continuous support. We thank A. Jenewein and F. Davison for excellent technical assistance.

1. Nishizuka, Y. 1988. The molecular heterogeneity of protein kinase C and its implications for cellular regulation. Nature. 334:661-665.

2. Ron, D., and Kazanietz, M.G. 1999. New insights into the regulation of protein kinase $\mathrm{C}$ and novel phorbol ester receptors. FASEB J. 13:1658-1676

3. Dempsey, E.C., et al. 2000. Protein kinase C isozymes and the regulation of diverse cell responses. Am. J. Physiol. 279:L429-L438.

4. Fukumoto, S., et al. 1997. Protein kinase C delta inhibits the proliferation of vascular smooth muscle cells by suppressing G1 cyclin expression. J. Biol. Chem. 272:13816-13822.

5. Li, W., et al. 1998. Protein kinase C-delta is an important signaling molecule in insulin-like growth factor I receptor-mediated cell transformation. Mol. Cell. Biol. 18:5888-5898.

6. Li, P.F., Maasch, C., Haller, H., Dietz, R., and von Harsdorf, R. 1999. Requirement for protein kinase $\mathrm{C}$ in reactive oxygen species-induced apoptosis of vascular smooth muscle cells. Circulation. 100:967-973.

7. Majumder, P.K., et al. 2000. Mitochondrial translocation of protein kinase $C$ delta in phorbol ester-induced cytochrome c release and apoptosis. J. Biol. Chem. 275:21793-21796.

8. Sun, Z., et al. 2000. PKC-theta is required for TCR-induced NF-kappaB activation in mature but not immature $\mathrm{T}$ lymphocytes. Nature. 404:402-407.

9. Motwani,J.G., and Topol, E.J. 1998. Aortocoronary saphenous vein graft disease: pathogenesis, predisposition, and prevention. Circulation. 97:916-931.

10. Ross, R. 1993. The pathogenesis of atherosclerosis: a perspective for the 1990s. Nature. 362:801-809.

11. Xu, Q. 2000. Biomechanical-stress-induced signaling and gene expression in the development of arteriosclerosis. Trends Cardiovasc. Med. 10:35-41.

12. Bennett, M., et al. 1998. Cell surface trafficking of Fas: a rapid mechanism of p53-mediated apoptosis. Science. 282:290-293.

13. Mayr, M., and Xu, Q. 2001. Smooth muscle cell apoptosis in arteriosclerosis. Exp. Gerontol. 36:969-987.

14. Ghayur, T., et al. 1996. Proteolytic activation of protein kinase C delta by an ICE/CED 3-like protease induces characteristics of apoptosis. J. Exp. Med. 184:2399-2404.

15. Doetschman, T., et al. 1987. Targeted correction of a mutant HPRT gene in mouse embryonic stem cells. Nature. 330:576-578.

16. Zou, Y., et al. 1998. Mouse model of venous bypass graft arteriosclerosis. Am. J. Pathol. 153:1301-1310.

17. Dietrich, H., et al. 2000. Rapid development of vein graft atheroma in ApoE-deficient mice. Am. J. Pathol. 157:659-669.

18. Zou, Y., et al. 2000. Reduced neointima hyperplasia of vein bypass grafts in intercellular adhesion molecule-1-deficient mice. Circ. Res. 86:434-440.

19. Mayr, M., et al. 2000. Biomechanical stress-induced apoptosis in vein grafts involves p38 mitogen-activated protein kinases. FASEB J. $14: 261-270$
20. Hu, Y., Zou, Y., Dietrich, H., Wick, G., and Xu, Q. 1999. Inhibition of neointima hyperplasia of mouse vein grafts by locally applied suramin. Circulation. 100:861-868.

21. Li, C., Hu, Y., Mayr, M., and Xu, Q. 1999. Cyclic strain stress-induced mitogen-activated protein kinase (MAPK) phosphatase 1 expression in vascular smooth muscle cells is regulated by Ras/Rac-MAPK pathways. J. Biol. Chem. 274:25273-25280.

22. Mancini, M., et al. 1997. Mitochondrial proliferation and paradoxical membrane depolarization during terminal differentiation and apoptosis in a human colon carcinoma cell line. J. Cell Biol. 138:449-469.

23. Miller, F.J., Jr., Gutterman, D.D., Rios, C.D., Heistad, D.D., and Davidson, B.L. 1998. Superoxide production in vascular smooth muscle contributes to oxidative stress and impaired relaxation in atherosclerosis. Circ. Res. 82:1298-1305.

24. Cepinskas, G., Lush, C.W., and Kvietys, P.R. 1999. Anoxia/reoxygenationinduced tolerance with respect to polymorphonuclear leukocyte adhesion to cultured endothelial cells. A nuclear factor-kappaB-mediated phenomenon. Circ. Res. 84:103-112.

25. Shaulian, E., et al. 2000. The mammalian UV response. c-Jun induction is required for exit from p53-imposed growth arrest. Cell. 103:897-907.

26. Zhou, X., Zhai, X., and Ashraf, M. 1997. Direct evidence that initial oxidative stress triggered by preconditioning contributes to second window of protection by endogenous antioxidant enzyme in myocytes. Circulation. 93:1177-1184.

27. Wang, Q.J., et al. 1999. Differential localization of protein kinase C delta by phorbol esters and related compounds using a fusion protein with green fluorescent protein. J. Biol. Chem. 274:37233-37239.

28. Benna, J.E., Faust, L.R.P., Johnson, J.L., and Babior, B.M. 1996. Phosphorylation of the respiratory burst oxidase subunit $\mathrm{p} 47$ as determined by two-dimensional phosphopeptide mapping. J. Biol. Chem. 271:6374-6378.

29. Geng, Y.J., and Libby, P. 1995. Evidence for apoptosis in advanced human atheroma. Colocalization with interleukin-1 beta-converting enzyme. Am. J. Pathol. 147:251-266.

30. Bennett, M.R., Evan, G.I., and Schwartz, S.M. 1995. Apoptosis of human vascular smooth muscle cells derived from normal vessels and coronary atherosclerotic plaques. J. Clin. Invest. 95:2266-2274.

31. Isner, J.M., Kearney, M., Bortman, S., and Passeri, J. 1995. Apoptosis in human atherosclerosis and restenosis. Circulation. 91:2703-2711.

32. Han, D.K., et al. 1995. Evidence for apoptosis in human atherogenesis and in a rat vascular injury model. Am. J. Pathol. 147:267-277.

33. Patel, V.A., et al. 2001. Defect in insulin-like growth factor-1 survival mechanism in atherosclerotic plaque-derived vascular smooth muscle cells is mediated by reduced surface binding and signaling. Circ. Res. 88:895-902.

34. Bowen-Pope, D.F., and Schaub, F.J. 2001. Apoptosis of smooth muscle cells is not silent: Fas/FADD initiates a program of inflammatory gene expression. Trends Cardiovasc. Med. 11:42-45.

35. Mallat, Z., and Tedgui, A. 2001. Current perspective on the role of apoptosis in atherothrombotic disease. Circ. Res. 88:998-1003.

36. George, S.J., Angelini, G.D., Capogrossi, M.C., and Baker, A.H. 2001 Wild-type p53 gene transfer inhibits neointima formation in human saphenous vein by modulation of smooth muscle cell migration and induction of apoptosis. Gene Ther. 8:668-676.

37. Mehrabian, M., et al. 2001. Genetic locus in mice that blocks development of atherosclerosis despite extreme hyperlipidemia. Circ. Res. 89:125-130.

38. Li, L., Lorenzo, P.S., Bogi, K., Blumberg, P.M., and Yuspa, S.H. 1999. Protein kinase Cdelta targets mitochondria, alters mitochondrial membrane potential, and induces apoptosis in normal and neoplastic keratinocytes when overexpressed by an adenoviral vector. Mol. Cell. Biol. 19:8547-8558.

39. Emoto, Y., et al. 1995. Proteolytic activation of protein kinase C delta by an ICE-like protease in apoptotic cells. EMBO J. 14:6148-6156

40. Reyland, M.E., Anderson, S.M., Matassa, A.A., Barzen, K.A., and Quissell, D.O. 1999. Protein kinase $C$ delta is essential for etoposide-induced apoptosis in salivary gland acinar cells. J. Biol. Chem. 274:19115-19123.

41. Li, C., Hu, Y., Sturm, G., Wick, G., and Xu, Q. 2000. Ras/rac-dependent activation of $\mathrm{p} 38$ mitogen-activated protein kinases in smooth muscle cells stimulated by cyclic strain stress. Arterioscler. Thromb. Vasc. Biol. 20.E1-E9. 